\title{
A switched reluctance motor control method limiting the maximum dc source current in the low-speed range
}

\author{
P. BOGUSZ* \\ Faculty of Electrical and Computer Engineering, Rzeszów University of Technology, 2 W. Pola St., 35-959 Rzeszow, Poland
}

\begin{abstract}
This paper presents a proposal of a new control method of the switched reluctance motor (SRM) in the low-speed range. The proposed method limits the maximum value of SRM drive supply current. The application of this method results also in improvement of the drive efficiency compared to the classical current control method, so it can be applied to control switched reluctance motors designed to the electric vehicles drive. The method may be effective especially in congested traffic. Nowadays, the urban traffic is characterized by frequent occurrence of traffic jams in which cars move at low speeds. The sources of supply for electric vehicles are mainly electrochemical batteries. Reduction of the maximum value of supply current allows to extend the service life of batteries and improvement of the drive efficiency extends the vehicle range.
\end{abstract}

Key words: switched reluctance motor, current control, electric vehicle.

\section{Introduction}

Traffic jams are the main cause for which it is usually no longer possible to drive a car along streets of modern cities at uniform speed. Getting stuck in a traffic jam, in a car, with the classic internal-combustion engine (ICE) causes unnecessary consumption of fuel. Modern cars with ICE are equipped with Start/Stop system which automatically turns off the engine once the vehicle is stopped and restarts it when the accelerator pedal is depressed again. A very good solution, in this case, it is the use of either electric or hybrid propulsion system which does not consume any energy when the vehicle is stopped $[1,2]$. One of several types of machines which are used to drive electric vehicles are switched reluctance motors (SRM). Switched reluctance machines are characterized by a simple construction, fault tolerance, and a wide speed range. These features make them an attractive candidate for electric and traction drives [3-5]. With the aim to ensure the maximum possible range of vehicles supplied from electrochemical batteries or fuel cells, a lot of effort is put in optimizing algorithms used to control electric drive systems from the point of view of their effectiveness [6]. Reduction of energy consumption in electric vehicles can be achieved by optimizing a driving style, introducing an appropriate energy management in the power system [7, 8], or employing new power systems [9-11]. Moreover, power consumption can be reduced by introducing new control algorithms in existing electric drive systems [12]. Driving a car in traffic jams occurs usually at very low speeds. In this paper, a new control method of switched reluctance motor designated to electric vehicle drive is presented. The method is designed especially for controlling SRM in low-speed operation. Application of the proposed method allows to limit the maximum value of supply current and increase the drive efficiency in the considered speed range.

\section{Mathematical model}

The mathematical model of SRM, in the general case of nonlinearity of the magnetic circuit can be expressed in the form:

$$
\begin{gathered}
\mathbf{u}=\mathbf{R i}+\frac{d}{d t}[\boldsymbol{\psi}(\theta, \mathbf{i})], \\
J \frac{d \omega}{d t}+D \omega+T_{L}=T_{e}, \\
\frac{d \theta}{d t}=\omega, \\
T_{e}=\frac{\partial W^{*}(\theta, \mathbf{i})}{\partial \theta},
\end{gathered}
$$

where individual vectors representing voltages on the terminal windings, currents, and flux-linkages, as well as the matrix of phase resistances are defined as:

$$
\begin{gathered}
\mathbf{u}=\left[u_{1}, \ldots, u_{N}\right]^{T}, \quad \mathbf{i}=\left[i_{1}, \ldots, i_{N}\right]^{T}, \\
\psi(\theta, \mathbf{i})=\left[\psi_{1}\left(\theta, i_{1}, \ldots, i_{N}\right), \ldots, \psi_{N}\left(\theta, i_{1}, \ldots, i_{N}\right)\right]^{T}, \\
\mathbf{R}=\operatorname{diag}\left(R^{1}, \ldots, R^{N}\right),
\end{gathered}
$$

respectively. Moreover, the following symbols have been used in formulas (1)-(4): $N$ - number of stator phases; $\theta$ - rotor position, $\omega$ - angular velocity, $J$ - moment of inertia, $D$ coefficient of viscous friction, $T_{L}-$ load torque and $W^{*}(\theta, \mathbf{i})$ - electromagnetic co-energy. Formula (4) determines the electromagnetic torque of the motor. It can be expressed in the form:

$$
T_{e}=\sum_{k=1}^{N} \frac{\partial}{\partial \theta} \int_{0}^{i_{k}} \psi_{k}\left(\theta, i_{1}, \ldots, \bar{i}_{k}, 0, \ldots, 0\right) d \bar{i}_{k}
$$

\footnotetext{
*e-mail: pbogu@prz.edu.pl
} 
In practice, a full symmetry of motor design is frequently assumed, with neglected magnetic couplings between phases and the dependence between the flux $\psi_{k}\left(\theta, i_{k}\right)$ and the current $i_{k}(k=1,2, \ldots, N)$ determined in the form

$$
\psi_{k}\left(\theta, i_{k}\right)=L_{k}\left(\theta, i_{k}\right) i_{k},
$$

where $L_{k}\left(\theta, i_{k}\right)$ is nonlinear self-inductance coefficient of $k$ th phase. With such assumptions, motor Eqs. (1) and (4) can be transformed into the form $(k=1,2, \ldots, N)$ :

$$
\begin{gathered}
u_{k}=R_{k} i_{k}+L_{d k}\left(\theta, i_{k}\right) \frac{d i_{k}}{d t}+\omega G_{k}\left(\theta, i_{k}\right) i_{k}, \\
T_{e}=\sum_{k=1}^{N} \frac{\partial W_{k}^{*}\left(\theta, i_{k}\right)}{\partial \theta},
\end{gathered}
$$

where

$$
\begin{gathered}
L_{d k}\left(\theta, i_{k}\right)=L_{k}\left(\theta, i_{k}\right)+i_{k} \frac{\partial L_{k}\left(\theta, i_{k}\right)}{\partial i_{k}}, \\
G_{k}\left(\theta, i_{k}\right)=\frac{\partial L_{k}\left(\theta, i_{k}\right)}{\partial \theta} .
\end{gathered}
$$

In Eq. (8) $W_{k}^{*}\left(\theta, i_{k}\right)$ represents the co-energy of $k$-th phase $(k=1,2, \ldots, N)$. Individual components of the right-hand side of Eq. (7) represent the resistance voltage drop, the transformation voltage, and the back-EMF $e$, respectively.

The electromagnetic torque $T_{e}$ from formula (8) by assuming (6) can be written as:

$$
T_{e}=\sum_{k=1}^{N} \frac{\partial}{\partial \theta} \int_{0}^{i_{k i}}\left(L_{k}\left(\theta, \bar{i}_{k}\right) \bar{i}_{k}\right) d \bar{i}_{k} .
$$

Individual components of the right-hand side of Eq. (11) represent component torques from currents of particular phases, respectively.

\section{Classical control method}

The source current ripple level depends on the maximum value of phase current $\left(I_{\max }\right)$, control angles $\left(\theta_{\text {on }}, \theta_{\text {off }}\right)$, and capacitance $(C)$ of the filter capacitor. Reduction of the source current ripple results also in lower dc-link voltage ripple. The paper [13] proposes an algorithm to reduce dc-link voltage ripple. However, specific cases considered in the above-quoted paper did not include motor control with overlapping intervals of conduction periods of individual phases. Another solution to reduce the source current ripple or to correct power factor consists in using an additional converter between the supply source and the SRM converter [14].

In electric vehicles, when accelerating after a stop or driving at a low speed, it is necessary to use the current control. In SRM drives, when the current control is used, it is necessary to supply two windings within a certain rotor angle interval in order to avoid electromagnetic torque dips. To supply SRM drives, various power system configurations can be used [15], but the most universal is the half-bridge circuit with two transistors and two diodes per motor phase. A schematic diagram of a half-bridge $k$-phase SRM power converter is presented in Fig. 1. The current between the power circuit and the filter capacitor $C$ is denoted as $i_{\mathrm{dc}}$, while the source current is represented by $i_{\mathrm{dc}}^{*}$.

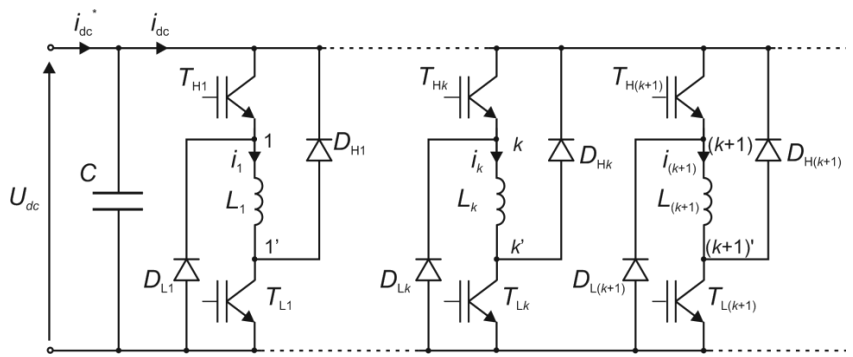

Fig. 1. A $k$-phase SRM power converter

The principle of operation of a single branch ( $k$-th phase) of the power circuit can be described as follows. If the transistors, the upper $\left(T_{\mathrm{H} k}\right)$ and the lower $\left(T_{\mathrm{L} k}\right)$, are switched on at the same time, the current is drawn from the voltage source and dc-link capacitor $C$. In case when only one transistor is switched on, current flows in the inner loop $L_{k}-D_{\mathrm{H} k}-T_{\mathrm{H} k}$ or $L_{k}-D_{\mathrm{L} k}-T_{\mathrm{L} k}$ as a result of energy stored in winding $L_{k}$. If both transistors are switched off, then the current freewheels through diodes $D_{\mathrm{H} k}$ and $D_{\mathrm{L} k}$ back to the supply source and dc-link capacitor $C$ (the energy return).

In case when two phases are supplied at the same time, the maximum value of the current $i_{\mathrm{dc}}$, i.e $I_{\mathrm{dcmax}}$, may be twice as high as the maximum value of phase current $\left(I_{\max }\right)$. Such a feature is particularly adverse in view of possible increase of electromagnetic interference and instantaneous overload of the dc source. Such an increase of the maximum value of source current up to $2 I_{\max }$ may occur e.g. in the classical current control (CCC) with the use of digital hysteresis current controller [16-17]. Operating functions of regulators of the outgoing phase $(k-1)$ and the incoming phase $(k)$ can be written as:

$$
\begin{gathered}
f_{k-1}=\left\{\begin{array}{lll}
0 & \text { if } & \left(e_{k-1} \leq 0\right) \\
1 & \text { if } & \left(e_{k-1}>0\right)
\end{array}\right\} \quad k=1, \ldots, N, \\
f_{k}=\left\{\begin{array}{lll}
0 & \text { if } & \left(e_{k} \leq 0\right) \\
1 & \text { if } & \left(e_{k}>0\right)
\end{array}\right\} \quad k=1, \ldots, N,
\end{gathered}
$$

where $e_{k-1}=I_{\text {ref }}-i_{k-1}$ is the outgoing phase current error, $e_{k}=I_{\text {ref }}-i_{k}$ is the incoming phase current error, and $I_{\text {ref }}$ is the reference current.

In general, the current regulator function for CCC method in the conduction period $\left\langle\theta_{\text {on }}, \theta_{\text {off }}\right\rangle$ can be written as:

$$
S_{k}^{\mathrm{CCC}}=\left\{f_{k} \quad \theta \in\left\langle\theta_{\text {on }(k)}, \theta_{\text {off }(k)}\right\rangle\right\} .
$$

The waveforms of phase currents $i$ and the source current $i_{\mathrm{dc}}$ are presented in Fig. 2.

In most cases, electric vehicles are supplied from electrochemical batteries, so currents with large magnitudes may have an adverse impact on their service life. Methods used to mitigate this effect include the use of a capacitor filter or an active filter.

This paper presents a dependent current control method (DCC) in which control function of incoming phase current 
depends on control function of outgoing phase current. The proposed method imposes a limit on the maximum value of supply current. In view of the fact that such reduction of the maximum value of source current would reduce its rms value, one can expect also reduction of power losses in a supply source and in power leads.

a)

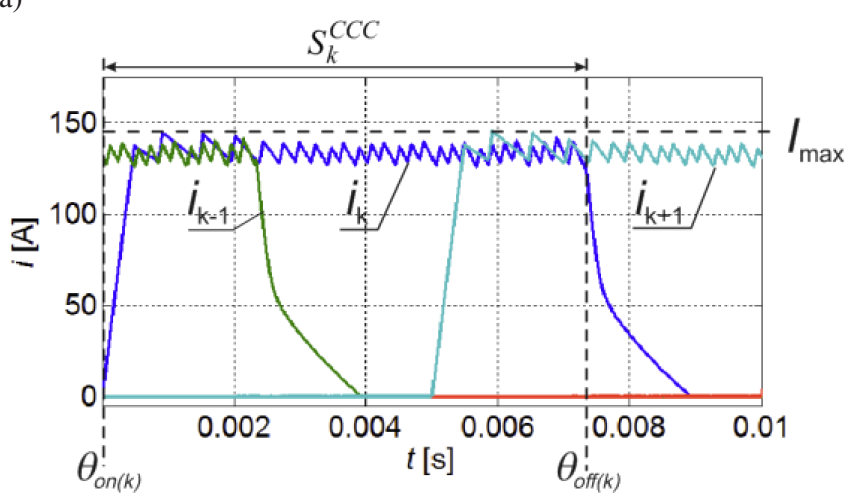

b)

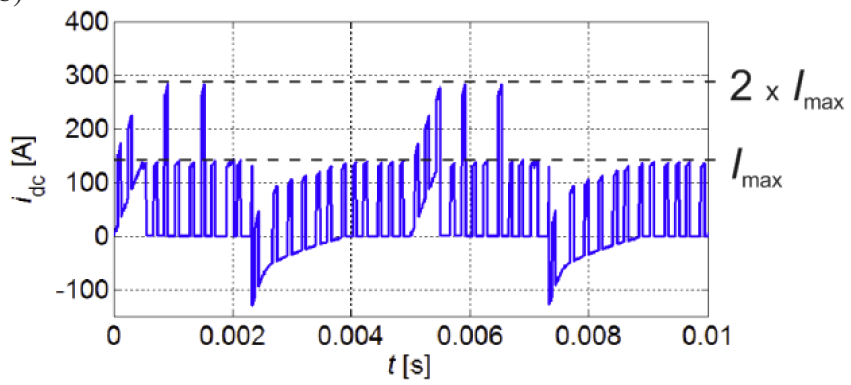

Fig. 2. a) Phase currents $(i)$; b) source current $i_{\mathrm{dc}}$ for the classical current control (CCC)

\section{Proposed control method}

In order to counteract the increase of the instantaneous source current up to the level $2 I_{\text {ref }}$, any two windings must not be supplied at the same time. If the conduction periods of any two neighboring phases overlap, transistors should be controlled in such a way that when one of phase windings is being supplied, the other is operating in zero-volt state or in de-fluxing period. In the motoring operation, each phase is supplied near unaligned position. At this moment, the time constant of circuit is small. Additionally, the derivative $\frac{\partial L_{k}\left(\theta, i_{k}\right)}{\partial \theta}$ in such a position of the rotor is close to zero which means that the back-EMF is also close to zero $(e \approx 0)$. As a result, the phase current increases very fast. In case when the rotor position is close to turn-off angle $\left(\theta_{\text {off }}\right)$, the time constant of circuit is larger than at turn-on angle $\left(\theta_{\text {on }}\right)$. Moreover, the derivative $\frac{\partial L_{k}\left(\theta, i_{k}\right)}{\partial \theta}$ reaches high values so phase current rises much slower than in unaligned position.

The current in the incoming phase increases much faster than this in the outgoing phase, so it may be concluded that with constant sampling time of current regulator $\left(t_{\text {samp }}\right)$, current changes in the incoming phase are much more significant that those occurring in the outgoing phase (i.e. $\mathrm{d} i_{k} / \mathrm{d} t<$ $\mathrm{d} i_{k+1} / \mathrm{d} t$ ). For this reason, the current decay time in the in- coming phase is much longer than this in the outgoing phase. Making use of this property, it is possible to make that operation of the current controller in the incoming phase is dependent on the state of the current controller in the outgoing phase.

When such control principle is being adopted, a problem occurs when incoming phase is supplied, and the current in this phase equals zero. At higher rotor speeds, the current rise time increases, and according to the proposed control principle, the controller in the outgoing phase must not be supplied as long as the state of the controller in the incoming phase is " 1 ". This results in a significant decrease of the current (and thus also the torque) in the outgoing phase. The problem is illustrated in Fig. 3.

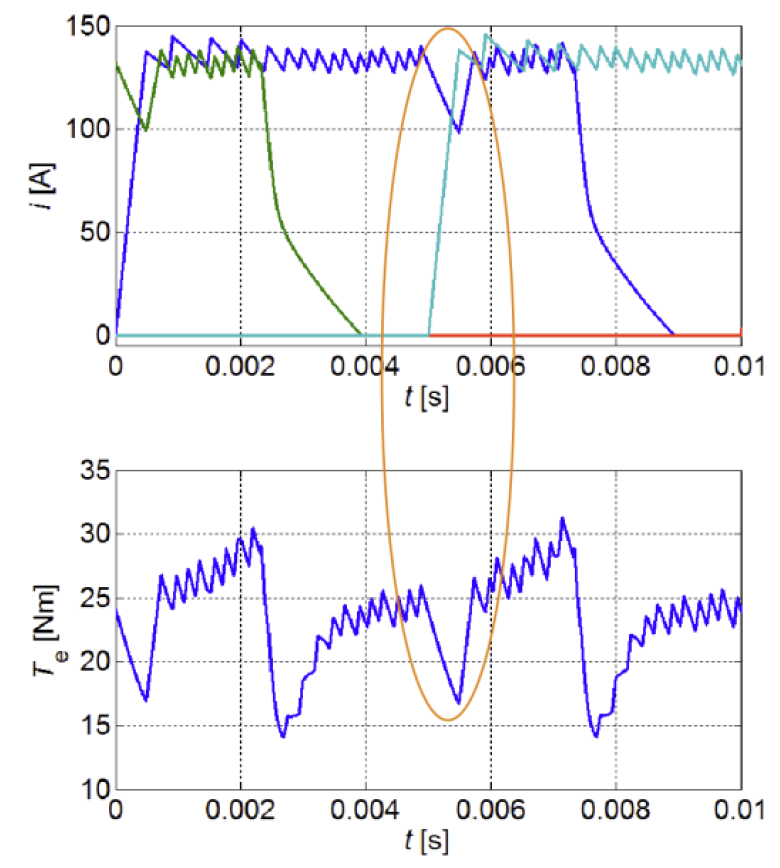

Fig. 3. Phase currents $(i)$ and the electromagnetic torque $\left(T_{e}\right)$ with the marked drop of phase current $i_{k}$ and torque $T_{e}$

In order to avoid such an adverse effect, an additional interval is introduced in which current in the incoming phase is controlled by the inverted outgoing phase control function $\overline{f_{i(k-1)}}$. Such a control method is justified because current increase in the incoming phase is faster than in the outgoing phase. The application of this method extends the current rise time compared to the CCC method. The conduction period $\left\langle\theta_{\text {on }}, \theta_{\text {off }}\right\rangle$ in the proposed method has been divided into three sub-intervals (cf. Fig. 4a):

- $\left\langle\theta_{\mathrm{on}(k)}, \theta_{\operatorname{Iref}(k)}\right\rangle$ - in which the phase current increases from 0 to the value of $I_{\operatorname{ref}(k)}$. Transistors of the $k$-th phase are switched on and switched off according to the inverted control function of the outgoing phase current controller $\left(\overline{\left.f_{i(k-1)}\right)}\right.$;

- $\left\langle\theta_{I \operatorname{ref}(k)}, \theta_{\text {off }(k-1)}\right\rangle$ - in which phase controllers $f_{i(k)}$ and $f_{i(k-1)}$ operate simultaneously, whereas the regulator $f_{i(k-1)}$ may be switched on when the value of control function $f_{i(k)}$ is zero; 
- $\left\langle\theta_{\text {off }(k-1)}, \theta_{\text {off }(k)}\right\rangle-$ in which the current is regulated according to function $f_{i(k)}$.

a)

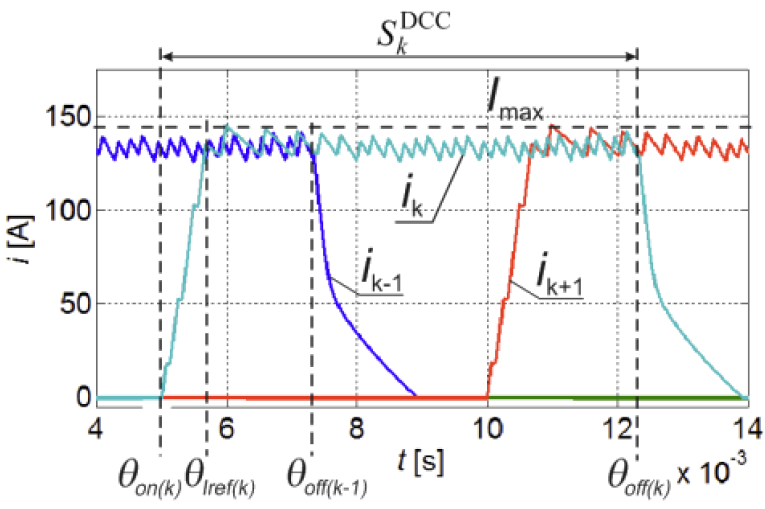

b)

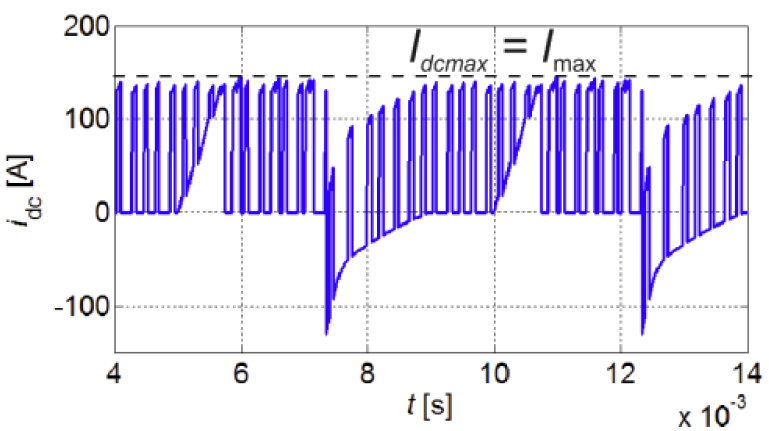

Fig. 4. a) Phase currents $(i)$; b) $i_{\mathrm{dc}}$ current for the DCC method

As it can be seen in Fig. 4b, the maximum value of current $i_{\mathrm{dc}}$ does not exceed the maximum value of phase currents $I_{\max }$, in contrast with the CCC method.

The current control function for the proposed DCC method can be written as:

$S_{k}^{\mathrm{DCC}}=\left\{\begin{array}{cc}\overline{f_{i(k-1)}} & \theta \in\left\langle\theta_{\mathrm{on}(k)}, \theta_{\operatorname{Iref}(k)}\right) \\ f_{i(k)} \text { and } \overline{f_{i(k-1)}} & \theta \in\left\langle\theta_{\operatorname{Iref}(k)}, \theta_{\mathrm{off}(k-1)}\right) \\ f_{i(k)} & \theta \in\left\langle\theta_{\mathrm{off}(k-1)}, \theta_{\mathrm{off}(k)}\right\rangle\end{array}\right\}$.

Figure 5 depicts the logic structure of current regulator of one phase in DCC method.

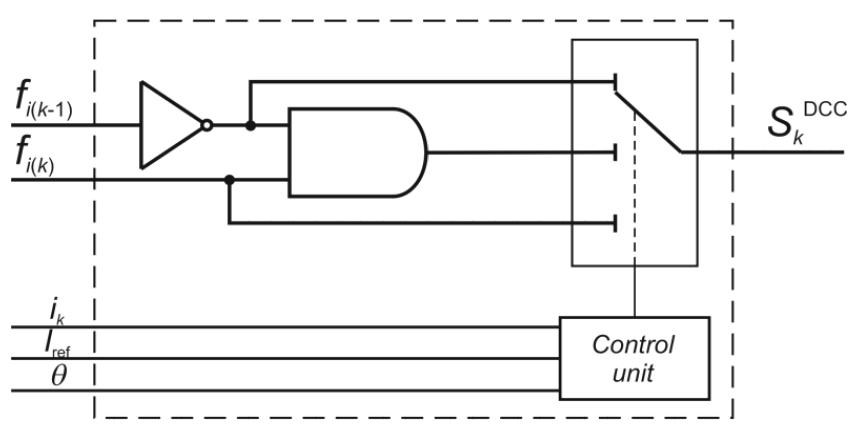

Fig. 5. A block diagram of the phase current $\left(i_{k}\right)$ regulator using the DCC method
In the DCC method, phase current in period $\left\langle\theta_{\text {on }(k)}, \theta_{\operatorname{Iref}(k)}\right\rangle$ rises slower than in CCC, because a mean value of phase voltage (with a neglected voltage drop of converter's semiconductor elements and motor power leads) equals:

$$
U_{a v(k)}=U_{\mathrm{dc}}-U_{a v(k-1)}
$$

where

$$
U_{a v(k-1)}=\frac{1}{\theta_{I \operatorname{ref}(k)}-\theta_{\operatorname{on}(k)}} \int_{\theta_{\text {on }(k)}}^{\theta_{I \operatorname{ref}(k)}} u_{(k-1)} d \theta
$$

is a mean value of phase voltage $(k-1)$ determined in period $\left\langle\theta_{\text {on }(k)}, \theta_{\text {Iref }(k)}\right\rangle$ (Fig. 6).

a)

b)
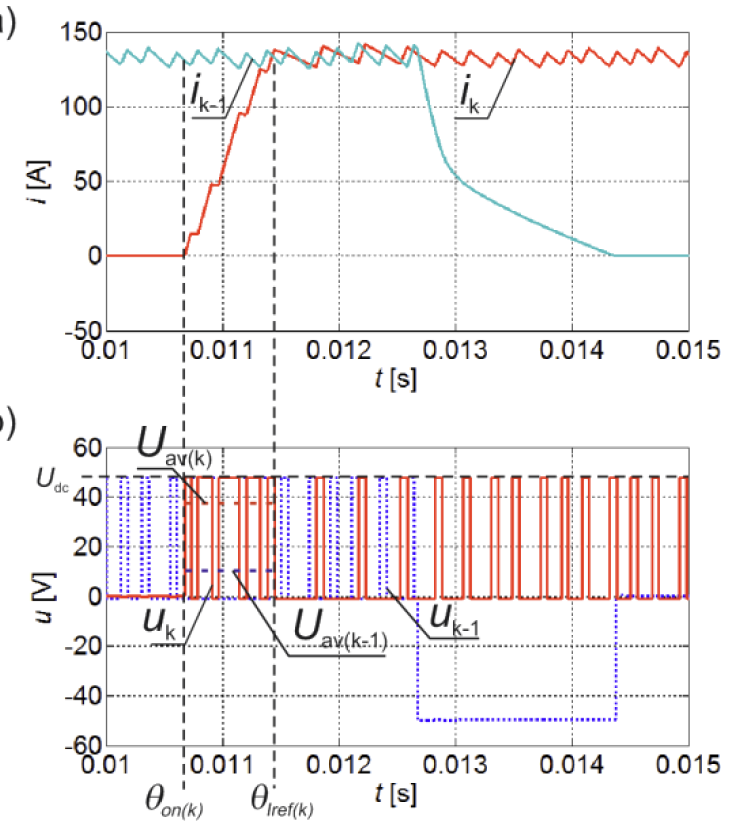

Fig. 6. Phase currents (a) and phase voltages (b) for DCC method

\section{Simulation results}

The simulation model of a four-phase SRM has been developed based on the presented mathematical model. Fundamental parameters of the SRM are listed in Table 1.

Table 1

Basic SRM data

\begin{tabular}{lc}
\hline \hline Machine type & SRM \\
\hline Number of phases & 4 \\
\hline Number of stator/rotor poles & $8 / 6$ \\
\hline Supply voltage & $48 \mathrm{~V}$ \\
\hline Rated power & $3.3 \mathrm{~kW}$ \\
\hline Maximum speed & $4500 \mathrm{rpm}$ \\
\hline
\end{tabular}

A nonlinear simulation model of the SRM was developed in MATLAB/Simulink where $i=f(\theta, \psi)$ and $T_{e}=f(\theta, i)$ characteristics were tabulated and they are presented in Fig. 7. Characteristic were determined using FEM, when a motor was designed. 
A switched reluctance motor control method limiting the maximum dc source current in the low-speed range

a)

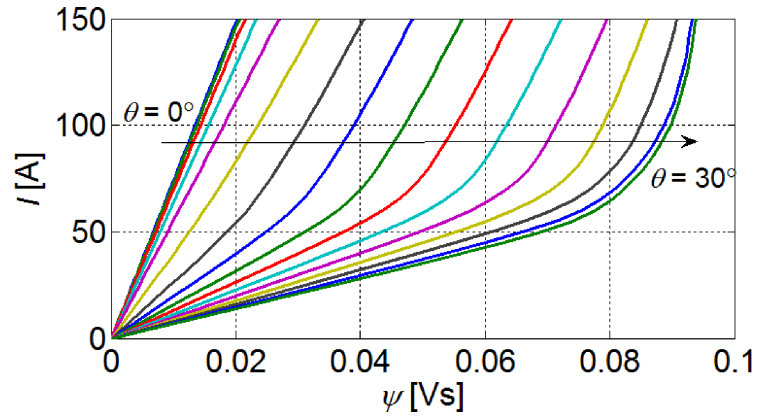

b)

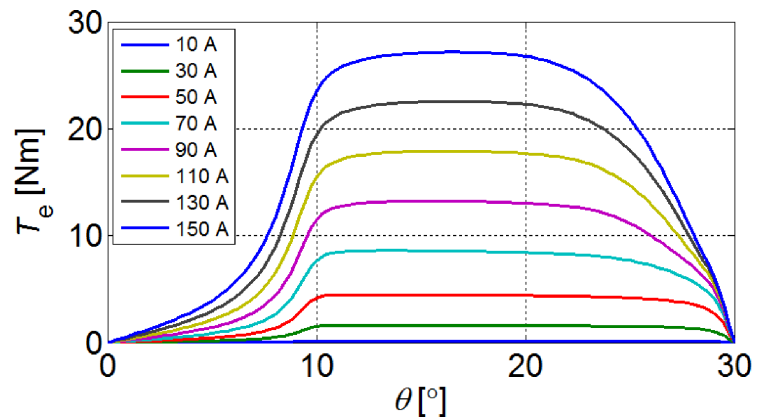

Fig. 7. Characteristics: a) $i=f(\theta, \psi)$; b) $T_{e}=f(\theta, i)$

Figure 8 shows the structure of the SRM simulation model. The discussed simulation model comprises the following blocks:

- resistance $R$ - containing resistances of individual phases;

- look-up table $i=f$ (theta, psi) - on the grounds of which phase currents of the machine are determined;
- torques $T_{e}$ - where the look-up table of $T_{e}=f(\theta, i)$ was placed.

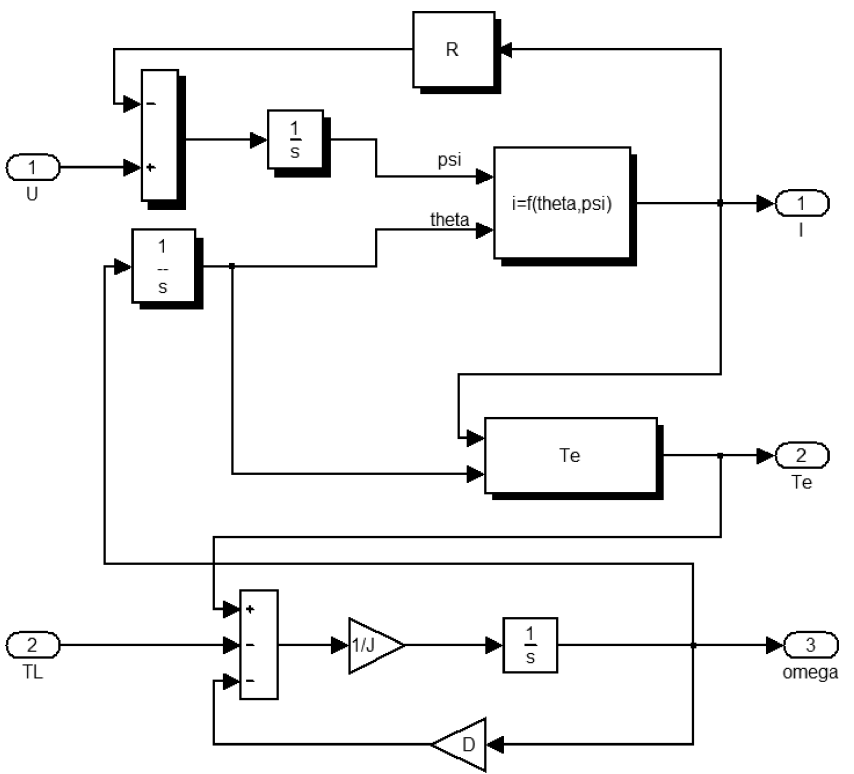

Fig. 8. A block structure of the simulation model of the SRM in MATLAB/Simulink

A schematic diagram of the block determining the electromagnetic torque is presented in Fig. 9. The block comprises the torque-current-angle characteristics of individual motor phases.

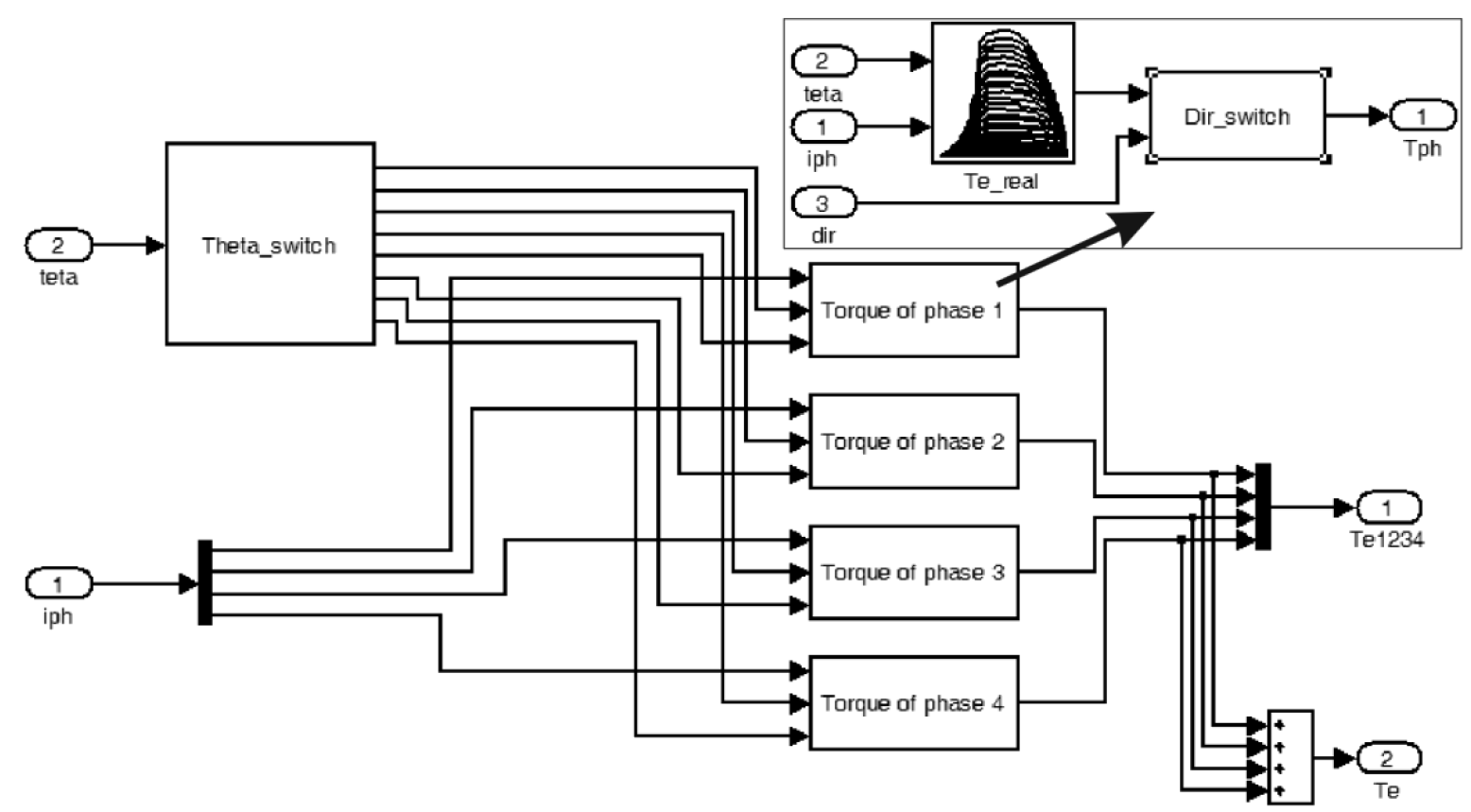

Fig. 9. A schematic diagram of the block determining the electromagnetic torque for individual phases of the motor 
P. Bogusz

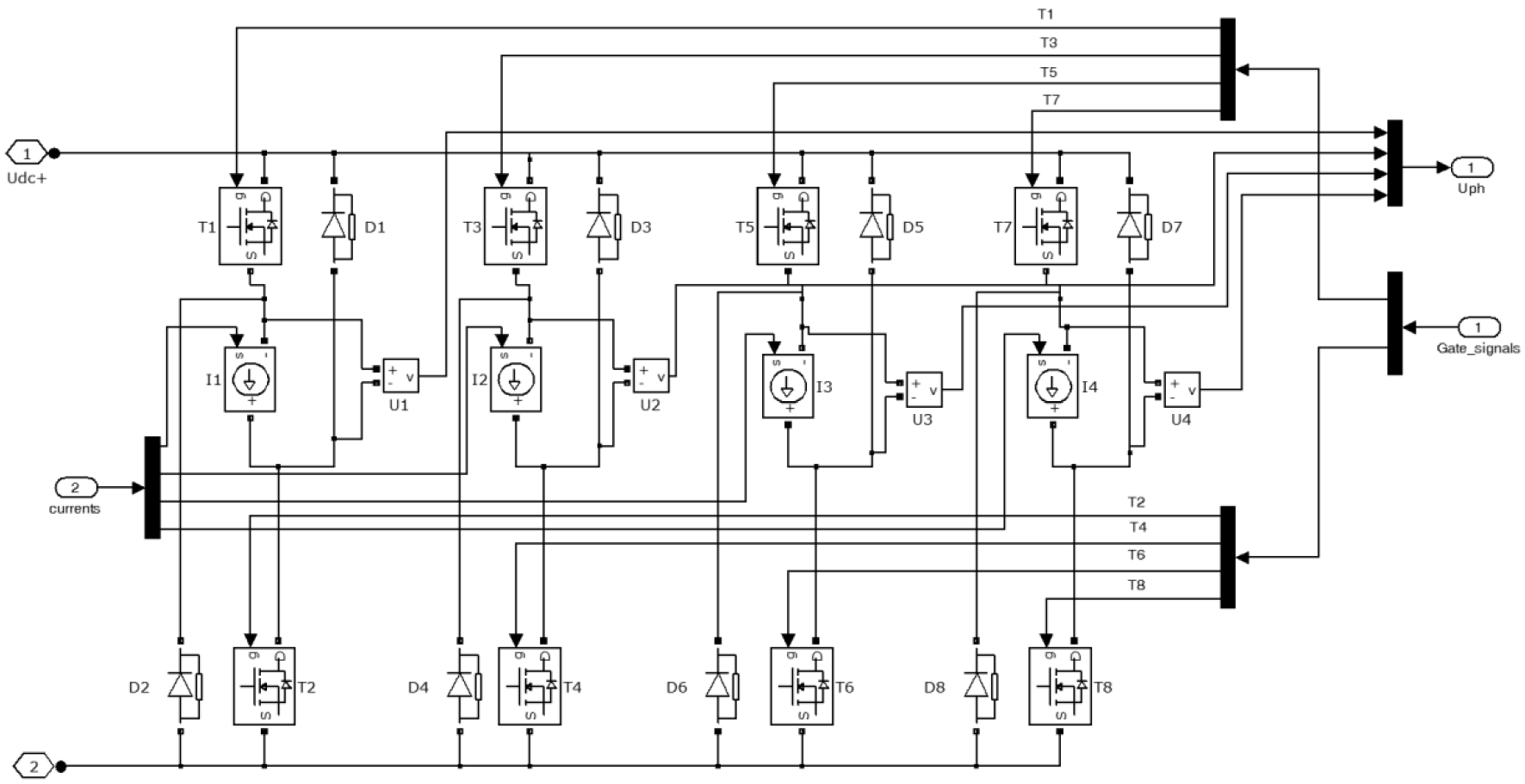

Fig. 10. SRM power converter module

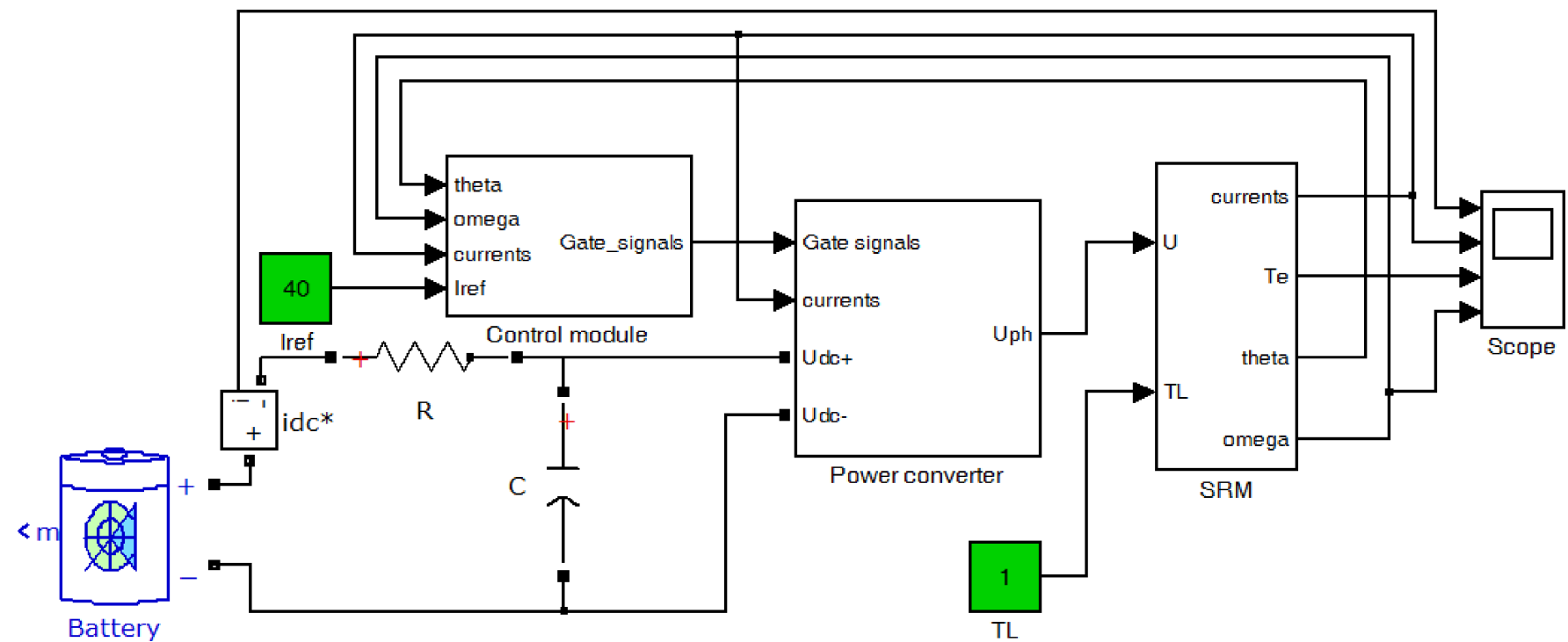

Fig. 11. Simulation model of the switched reluctance drive

A block diagram of the converter for a four-phase SRM (Power converter) is presented in Fig. 10.

The combination of the SRM model with the SRM drive system has been embodied by controlled current sources. A structure of the complete model of the SRM drive supplied from a battery is presented in Fig. 11. The model is divided into three blocks, i.e. the SRM and the Power converter (discussed above) as well as the Control module in which the drive control logic is integrated.

Figure 12 shows phase currents waveforms observed with the use of CCC (Fig. 12a) and DCC (Fig. 12b) methods for the motor speed $n=700 \mathrm{rpm}$ and $I_{\text {ref }}=67$ A. The as- sumed control angles in both of these cases were $\theta_{\text {on }}=3^{\circ}$ and $\theta_{\text {off }}=23^{\circ}$. The simulations were carried out with the use of a filter capacitor with capacity $C=6600 \mu \mathrm{F}$, i.e. the same as provided in the real system. For both considered control methods, differences in waveforms of the electromagnetic torque $T_{e}$ are small. Distinct differences can be seen in the source current $\left(i_{\mathrm{dc}}^{*}\right)$ waveforms. The maximum value of the source current $I_{\mathrm{dcmax}}^{*}$ in the CCC method exceeds $100 \mathrm{~A}$, whereas in the DCC method it reaches only the maximum phase current value, i.e. $67 \mathrm{~A}$. In the DCC method, phase currents rise significantly slower than in the CCC. 
A switched reluctance motor control method limiting the maximum dc source current in the low-speed range

a)
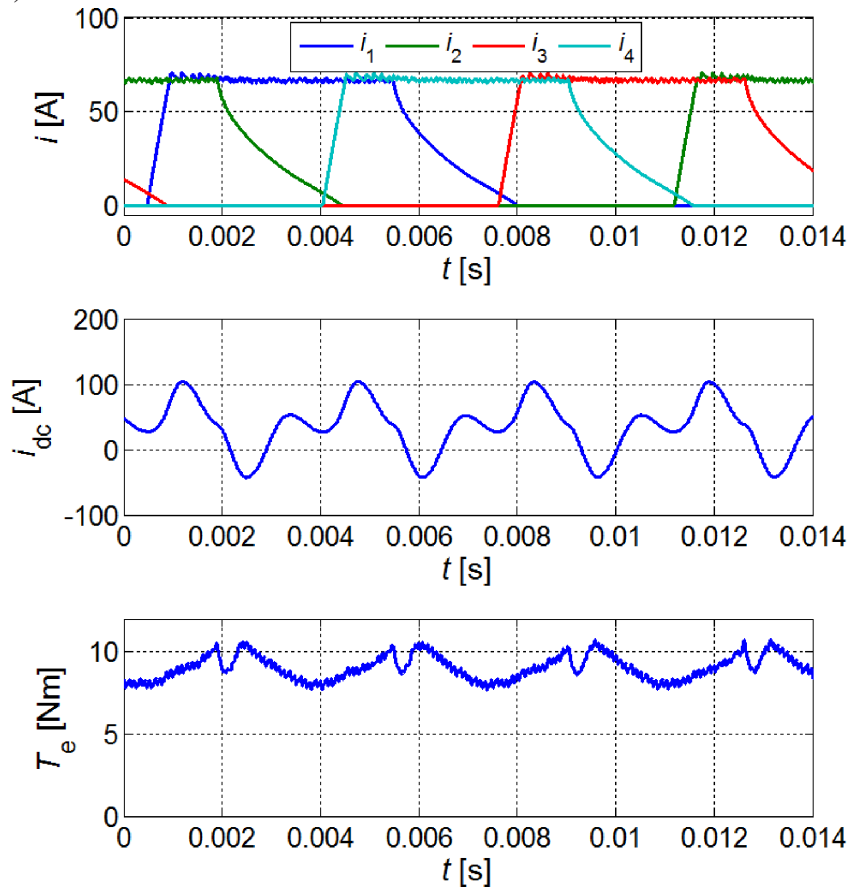

b)
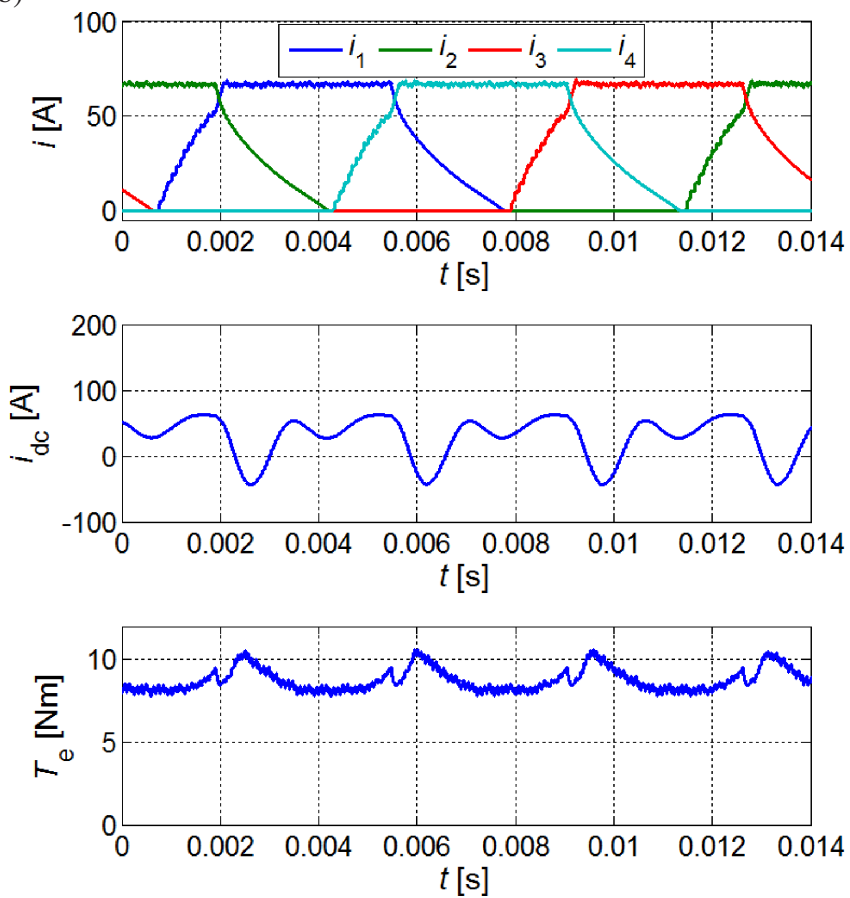

Fig. 12. Waveforms of phase currents $(i)$, source current $\left(i_{\mathrm{dc}}^{*}\right)$, and electromagnetic torque ( $\left.T_{e}\right)$ for: a) CCC; b) DCC, at $n=700 \mathrm{rpm}$ and $I_{\text {ref }}=67 \mathrm{~A}$

Figure 13 shows characteristics of torque mean value ( $T_{\text {eav }}$ as a function of motor speed $(n)$ for various turn-on angles $\left(\theta_{\text {on }}=-1, \ldots, 2^{\circ}\right)$ and conduction period equals $21^{\circ}$. Characteristics were determined for CCC (Fig. 13a) and DCC (Fig. 13b) methods. As it can be seen, the proposed DCC method has a lower speed range than CCC method. It can be also seen that in the proposed method a torque drop is significantly faster above a base speed. a)

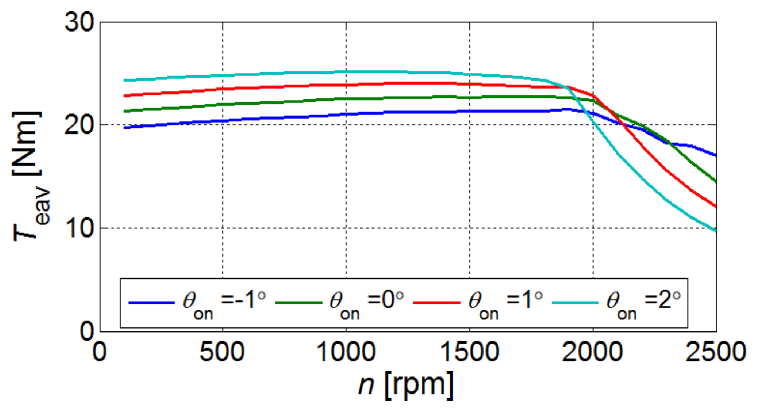

b)

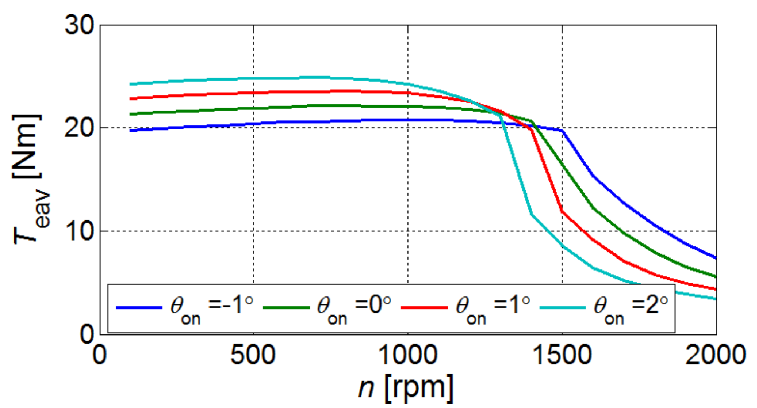

Fig. 13. Characteristics of torque mean value $\left(T_{\text {eav }}\right)$ as a function of motor speed ( $n$ ) for: a) CCC, b) DCC and various turn-on angles $\left(\theta_{\text {on }}\right)$

a)
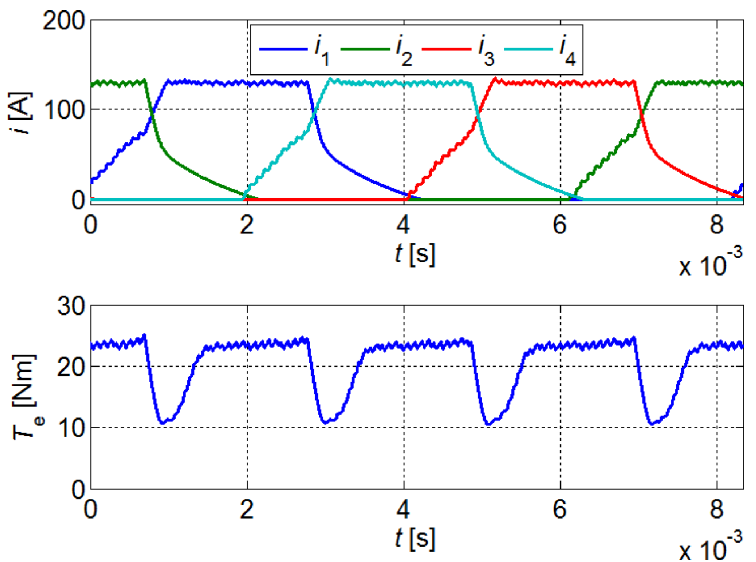

b)
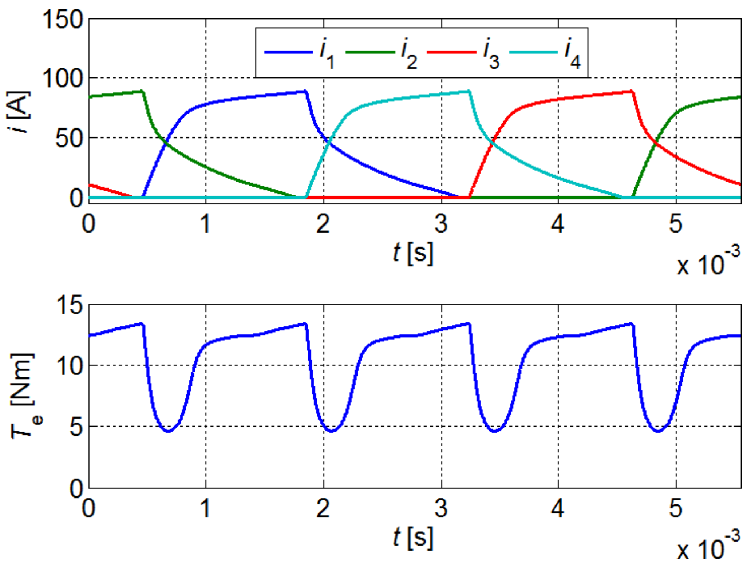

Fig. 14. Waveforms of phase currents $\left(i_{1}, i_{2}, i_{3}, i_{4}\right)$ and torque $\left(T_{e}\right)$ for DCC at speed: a) $n=1200 \mathrm{rpm}$, b) $n=1800 \mathrm{rpm}, \theta_{\mathrm{on}}=-1^{\circ}$, $\theta_{\text {off }}=20^{\circ}$ 
This arise from the fact that in DCC phase current in an incoming phase at higher speeds rises much slower than in the CCC method (Fig. 14a). When phase current does not reach the reference value, the incoming phase is supplied later (not at $\theta_{\text {on }(k)}$ but $\theta_{\text {off }(k-1)}-$ Fig. 14b), that leads to a significant drop in produced torque.

\section{Experimental results}

A laboratory setup with the SRM has been designed and constructed in order to verify simulation results [18]. Details of tested motor are listed in Table 1. A block diagram of the laboratory setup was presented in Fig. 15. The DS1103 PPC Controller Board by dSpace was used to control the drive. As a load, a separately excited dc machine was used controlled by programmable converter (Mentor). Figure 16 shows a view of the laboratory setup.

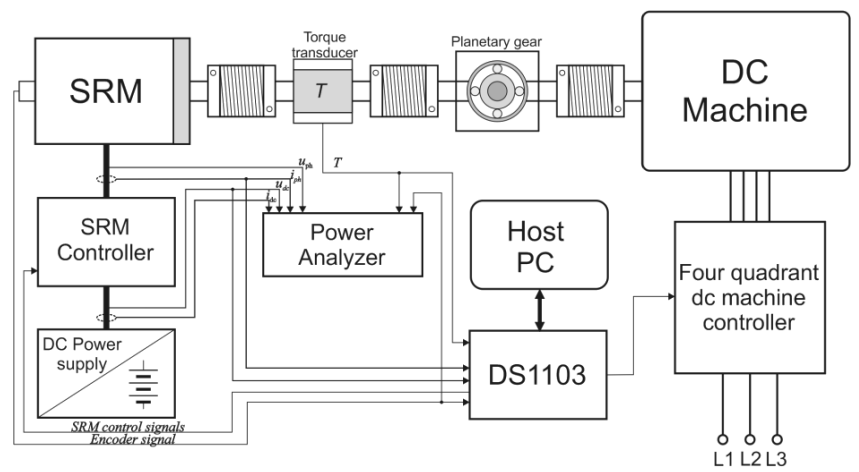

Fig. 15. A block diagram of the laboratory setup

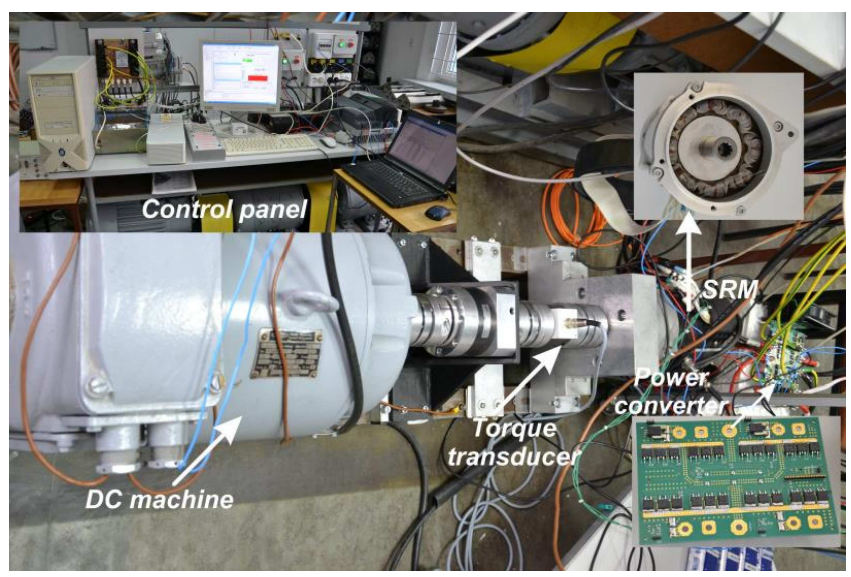

Fig. 16. The laboratory setup

Figures 17 and 18 show waveforms of phase currents and source currents for CCC and DCC, respectively. The waveforms were registered at the speed of $n=700 \mathrm{rpm}$. The motor was powered from an accumulator with rated voltage of $24 \mathrm{~V}$. The turn-on angle was set to $\theta_{\text {on }}=3^{\circ}$, and the turn-off angle to $\theta_{\text {off }}=23^{\circ}$. Comparing waveforms of the source current $i_{\mathrm{dc}}^{*}$ for both control schemes it can be easily seen that its maximum value has been significantly reduced in the case of the DCC method. However, the use of DCC results in much slower rise of phase currents. In order to compare drive parameters observed when using either CCC or the DCC method, characteristics of the maximum source current value $I_{\text {dcmax }}^{*}$ (Fig. 19) and the drive efficiency $\eta_{\text {total }}$ (Fig. 20) versus the load torque $T_{\mathrm{L}}$ have been determined at the motor speed of $n=1000 \mathrm{rpm}$ and the dc-link voltage $U_{\mathrm{dc}}=24 \mathrm{~V}$. In this case, the drive was powered from Agilent 6692A stabilized power-supply. The measurements were taken with the use of Yokogawa WT1800 power analyzer.

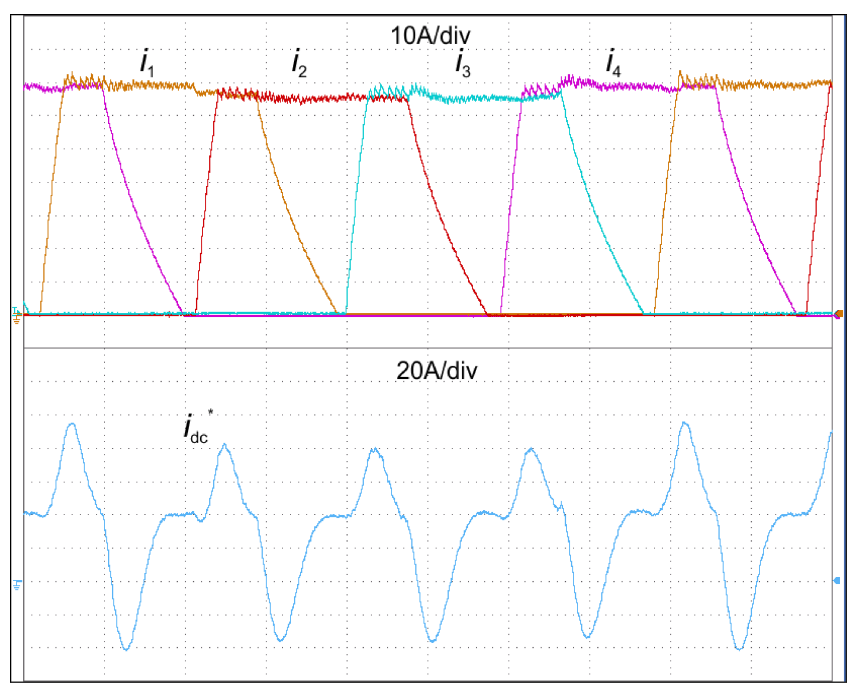

Fig. 17. An oscillogram of phase currents and source current for CCC method $\left(n=700 \mathrm{rpm}, U_{\mathrm{dc}}=24 \mathrm{~V}, \theta_{\mathrm{on}}=3^{\circ}, \theta_{\text {off }}=23^{\circ}\right)$

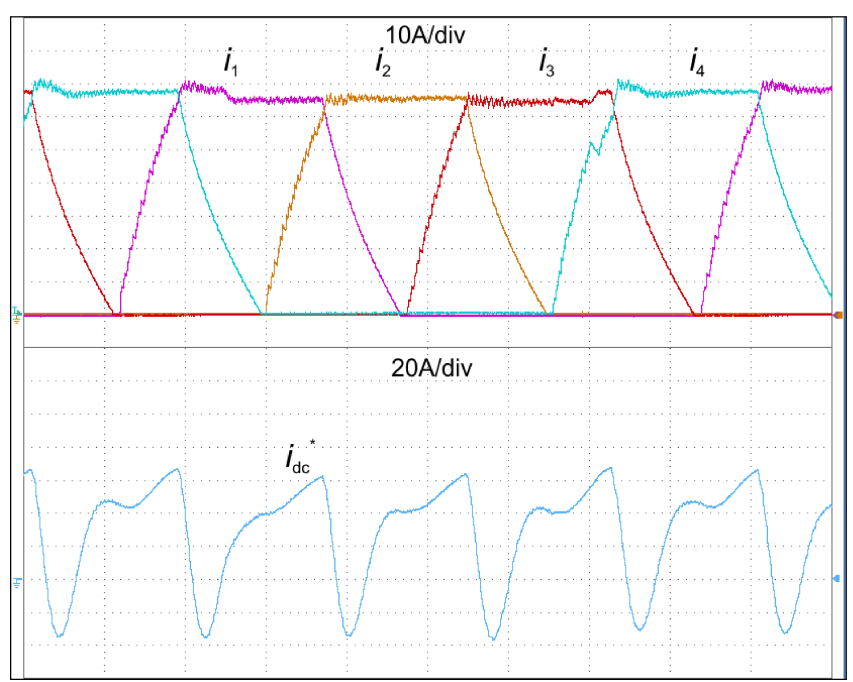

Fig. 18. An oscillogram of phase currents and source current for DCC method $\left(n=700 \mathrm{rpm}, U_{\mathrm{dc}}=24 \mathrm{~V}, \theta_{\mathrm{on}}=3^{\text {circ }}, \theta_{\text {off }}=23^{\circ}\right)$

When comparing the obtained results it can be seen that the maximum value of source current is much lower when the DCC method is used. The difference in $I_{\mathrm{dcmax}}^{*}$ by using both control methods increases significantly with increasing the load. It can be seen from Fig. 19 that when the DCC method is used, efficiency of the drive also increases with increasing load torque. 
A switched reluctance motor control method limiting the maximum dc source current in the low-speed range

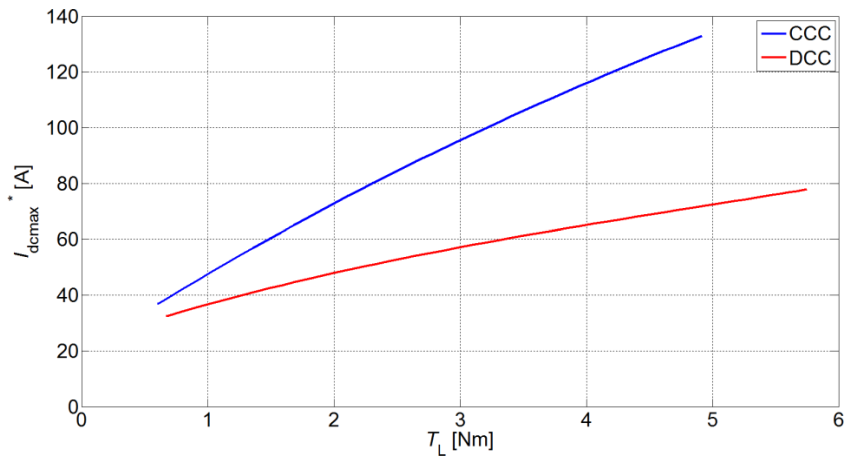

Fig. 19. Current characteristics $I_{\mathrm{dcmax}}^{*}$ as a function of a load torque for CCC and DCC methods $\left(n=1000 \mathrm{rpm}, U_{\mathrm{dc}}=24\right)$

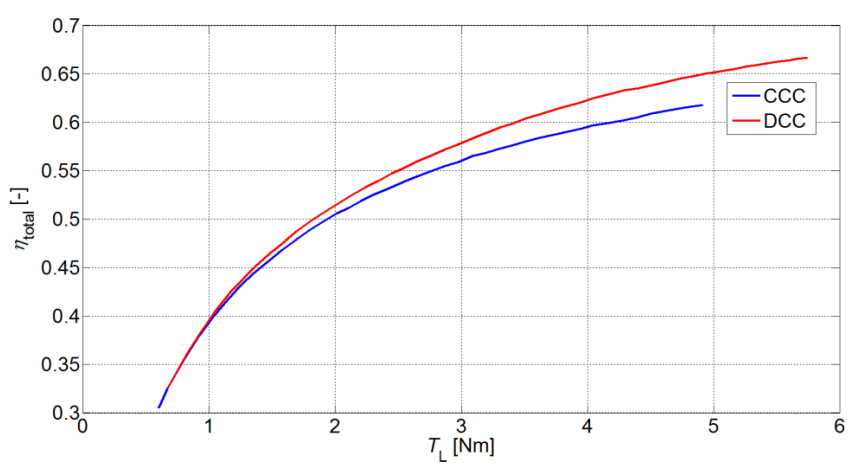

Fig. 20. Efficiency of the SRM drive as a function of a load torque for CCC and DCC methods ( $n=1000 \mathrm{rpm}, U_{\mathrm{dc}}=24 \mathrm{~V}$ )

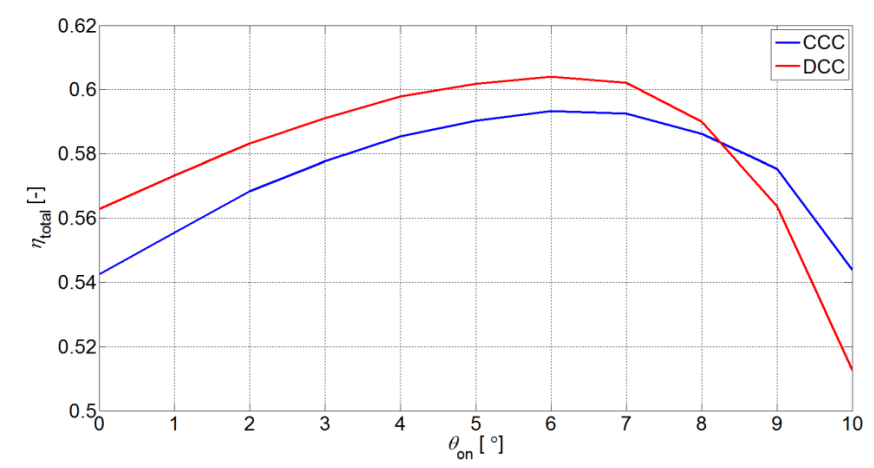

Fig. 21. Efficiency of the SRM drive $\left(\eta_{\text {total }}\right)$ as a function of turn-on angle $\left(\theta_{\text {on }}\right)$ at constant load torque $\left(T_{\mathrm{L}}=3 \mathrm{Nm}\right)$ for CCC and DCC

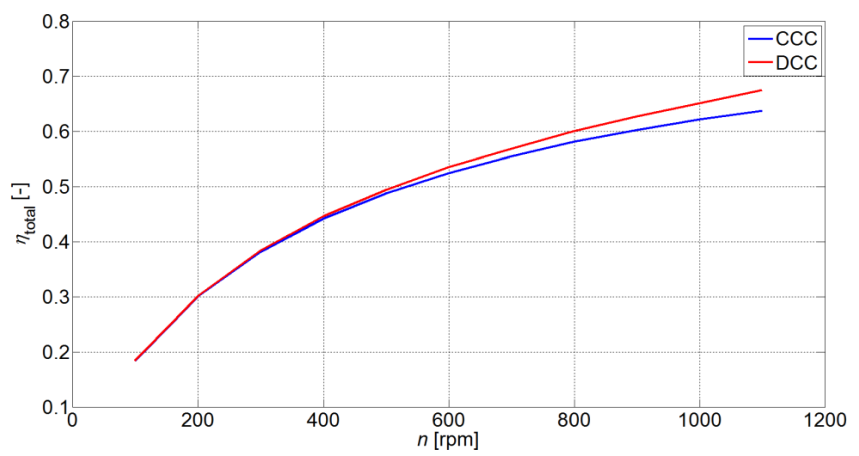

Fig. 22. Efficiency of the SRM drive $\left(\eta_{\text {total }}\right)$ as a function of motor speed $(n)$ at constant load torque $\left(T_{\mathrm{L}}=3 \mathrm{Nm}\right)$ for CCC and DCC

Figure 21 shows efficiency of the SRM drive as a function of turn-on angle at speed $n=700 \mathrm{rpm}$, load torque
$T_{L}=3 \mathrm{Nm}$, dc-link voltage $U_{\mathrm{dc}}=24 \mathrm{~V}$ for CCC and DCC. It can be seen that when turn-on angle is less than $8^{\circ}$, efficiency of the drive is larger in DCC method. Figure 22 shows efficiency as a function of motor speed at constant load torque $T_{\mathrm{L}}=3.65 \mathrm{Nm}, U_{\mathrm{dc}}=24 \mathrm{~V}$ and constant control angles $\left(\theta_{\text {on }}=0^{\circ}, \theta_{\text {off }}=24^{\circ}\right)$. It can be seen that efficiency in DCC method is larger than in CCC above speed $n=300 \mathrm{rpm}$. With increasing the motor speed, difference between efficiency in DCC and CCC also increases.

\section{Conclusions}

This paper presents a new dependent current control (DCC) method of switched reluctance motors (SRM) in the low-speed range. In the proposed method, operation of the phase current regulator depends on the state of the outgoing phase current regulator. Application of DCC provides the following advantages compared to the classical current control (CCC):

- limited maximum value of source current,

- increased efficiency, especially for higher load torques,

- the accumulator service life can be extended.

The proposed method has also following drawbacks:

- lower speed range than in the classical current control (CCC),

- necessity of control method change from DCC to CCC above the base speed.

The proposed DCC method may be used as a component of the global SRM control system in an electric vehicle.

\section{REFERENCES}

[1] M. Michalczuk, L.M. Grzesiak, and B. Ufnalski, "Hybridization of the lithium energy storage for an urban electric vehicle", Bull. Pol. Ac.: Tech. 61 (2), 325-333 (2013).

[2] M. Kozłowski and W. Choromański, "Dynamics simulation studies on the electric city car with an electromechanical differential and the rear wheels drive", Bull. Pol. Ac.: Tech. 61 (3), 661-673 (2013).

[3] H. Chang and Ch. Liaw, "An integrated driving/charging switched reluctance motor drive using three-phase power module", IEEE Trans. on Industrial Electronics 58 (5), 1763-1775 (2011).

[4] M. Takeno, A. Chiba, N. Hoshi, S. Ogasawara, M. Takemoto, and M. Azizur Rahman, "Test results and torque improvement of the 50-kw switched reluctance motor designed for hybrid electric vehicles", IEEE Trans. on Industry Applications 48 (4), 1327-1334 (2012).

[5] H. Chen and J.J. Gu, "Implementation of the three-phase switched reluctance machine system for motors and generators", IEEE/ASME Trans. on Mechatronics 15 (3), 421-432 (2010).

[6] W. Sung, Jincheol Shin, and Yu-seok Jeong, "Energy-efficient and robust control for high-performance induction motor drive with an application in electric vehicles", IEEE Trans. on Vehicular Technology 61 (8), 3394-3405 (2012).

[7] E. Kim, Jinkyu Lee, and K.G. Shin, "Real-time prediction of battery power requirements for electric vehicles", ACM/IEEE Int. Conf. on Cyber-Physical Systems (ICCPS) 1, 11-20 (2013). 
[8] M. Choi, S. Kim, and S. Seo, "Energy management optimization in a battery/supercapacitor hybrid energy storage system", IEEE Trans. on Smart Grid 3 (1), 463-472 (2012).

[9] H. Chang and Ch. Liaw, "An integrated driving/charging switched reluctance motor drive using three-phase power module", IEEE Trans. on Industrial Electronics 58 (5), 1763-1775 (2011).

[10] S. Tenner, S. Gunther, and W. Hofmann, "Loss minimization of electric drive systems using a DC/DC converter and an optimized battery voltage in automotive applications", IEEE Vehicle Power and Propulsion Conf. (VPPC) 1, 1-7 (2011).

[11] S. Tenner, S. Gunther, and W. Hofmann, "Loss minimization of electric drive systems using a Z-source inverter in automotive applications", Conf. on Power Electronics and Applications (EPE) 1, 1-8 (2013).

[12] V.P. Vujičicě, "Minimization of torque ripple and copper losses in switched reluctance drive", IEEE Trans. on Power Electronics 27 (1), 388-399 (2012).

[13] C.R. Neuhaus, N.H. Fuengwarodsakul, and R.W. De Doncker, "Control scheme for switched reluctance drives with min- imized DC-link capacitance", IEEE Trans. Power Electronics 23 (5), 2557-2564 (2008).

[14] M. Rajesh and B. Singh, "Analysis, design and control of single-phase three-level power factor correction rectifier fed switched reluctance motor drive", IET Power Electron. 7 (6), 1499-1508 (2014).

[15] R. Krishnan, Switched Reluctance Motor Drives - Modeling, Simulation, Analysis, Design, and Applications, CRC Press, Boca Raton, 2001.

[16] G. Gallegos-Lopez and K. Rajashekara, "Peak PWM current Control of Switched Reluctance and AC machines", Conf. Record Industry Applications 2002. 37th IAS Annual Meeting 2, 1212-1218 (2002).

[17] F. Blaabjerg, P.C. Kjaer, P.O. Rasmussen, and C. Cossar, "Improved digital current control methods in switched reluctance motor drives", IEEE Trans. on Power Electronics 14 (3), 563 572 (1999).

[18] P. Bogusz, "The laboratory stand for testing of light electric vehicles drives - design and implementation", Przeglad Elektrotechniczny 1, 16-19 (2014), (in Polish). 